\title{
Formation and optical properties of self-organized pentameric porphyrin arrays
}

\author{
Andrei V. Chernook ${ }^{a}$, Ulrich Rempel ${ }^{a}$, Christian von Borczyskowski ${ }^{a}$, \\ Alexander M. Shulga ${ }^{\text {}}$, Edward I. Zenkevich ${ }^{\mathrm{b}}$ \\ a Institut für Physik 13303, Technische Universität Chemnitz, D-09107 Chemnitz, Germany \\ ${ }^{b}$ Institute of Molecular and Atomic Physics, Academy of Sciences of Belarus, 70 Skaryna Av., Minsk 220072, Belarus
}

Received 6 November 1995; in final form 26 February 1996

\begin{abstract}
Principles of formation, electronic absorption and fluorescence spectra are reported for self-organized pentameric arrays of tetrapyrrolic macrocycles. In these arrays two molecules of $\mathrm{Zn}$-porphyrin dimers, $\mathrm{Zn}$ (II) 1,4-bis[5-(10,15,20-tri-p-hexylphenylporphyrinyl)]-benzene ((ZnHTPP $\left.)_{2}\right)$ are bound via one molecule of a tetrapyridyl-substituted free base of porphyrin or tetrahydroporphyrin. The process of self-assembly is based on the twofold coordination of the central $\mathrm{Zn}$ ions in the dimer with the nitrogen atoms of the pyridyl rings in the free base which is strong enough to make the complexes stable at room temperature. The formation of the complexes can be followed by changes in the absorption bands of (ZnHTPP) characteristic of an axial extra-ligation of $\mathrm{Zn}$-porphyrins with pyridine or pyridyl-substituted compounds. The spectral behavior of the free bases in the pentads is determined by a non-planar distortion of their macrocycle caused by the two-point binding with the dimers. The fluorescence intensity of the Zn-porphyrin dimer decreases essentially upon complexation with the tetrapyridyl-substituted free bases. This quenching effect is assigned to a singlet-singlet energy transfer from the complexed $\mathrm{Zn}$-porphyrin dimers to the free base subunit in the pentad.
\end{abstract}

\section{Introduction}

In order to model optical properties and primary photophysical processes in light-harvesting antennas and photosynthetic reaction centers many porphyrinand chlorophyll-based synthetic systems have been constructed and investigated over recent years [1-10]. The main purpose of these investigations was to understand the interplay between the structure of the model arrays and the efficiency of directional electronic excitation energy transfer (ET) and/or charge separation. Synthetic bisporphyrins bridged by various spacers have been shown to be useful and promising for studies of the details of primary photo- synthetic processes [5-8]. Currently much effort has been directed towards the creation and investigation of higher oligomers of porphyrins containing three or more covalently linked macrocycles [9-15]. On the other hand, self-assembly of molecular units in the frame of non-covalent supramolecular chemistry [16] is a highly promising way in terms of the considerable acceleration of constructing various architectures of light-harvesting and charge-transport systems. These ideas have already encouraged investigations on structurally organized aggregates of tetrapyrrolic macrocycles and their photophysical properties [17-19]. In these studies the self-organization was based mainly on such key-hole mechanisms 
as multipoint $\mathrm{H}$-bonding [17] and coulombic interactions of oppositely charged ionic substituents of the subunits $[18,19]$. Another approach is the coordina-
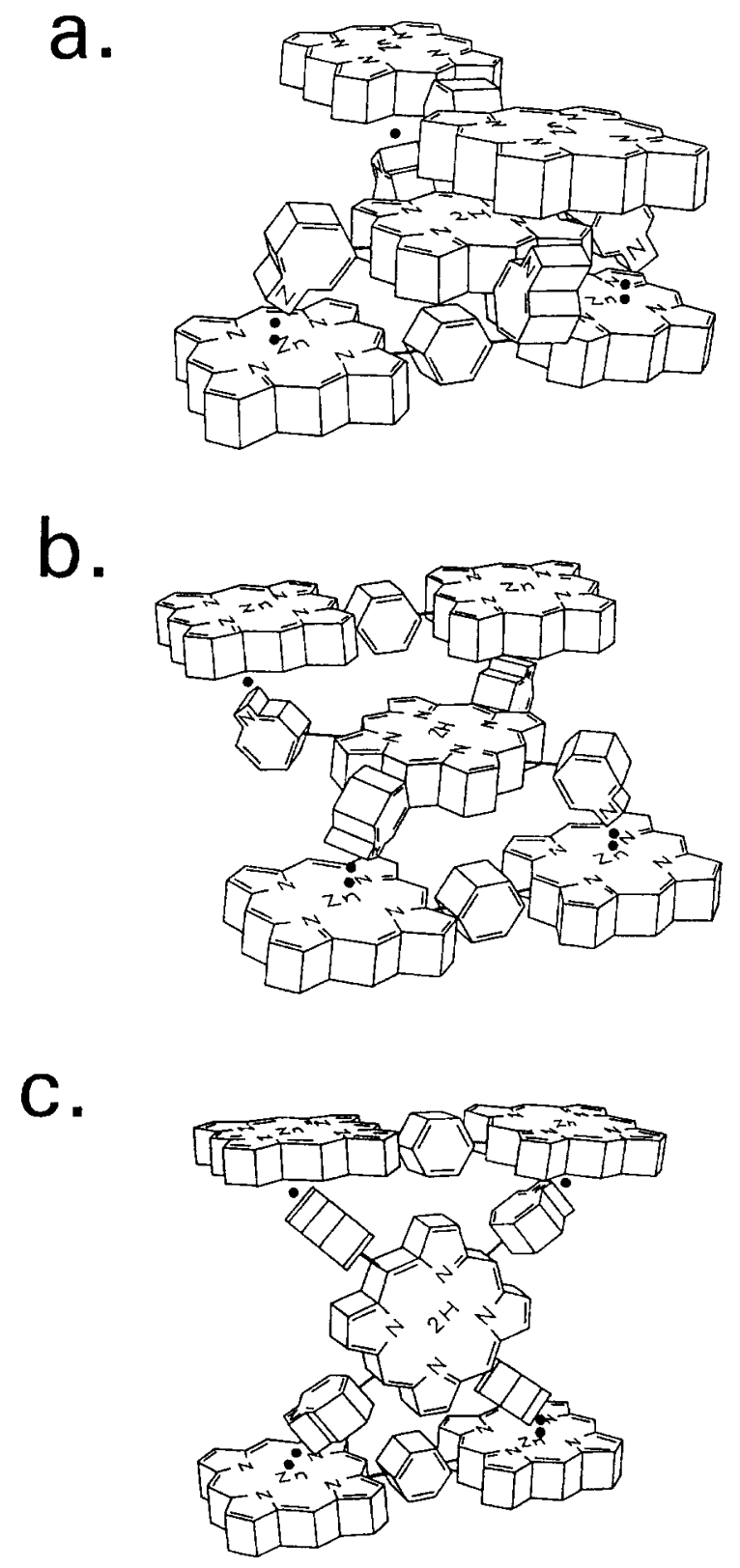

Fig. 1. Schematic representation of pentad structures. The hexylphenyl substituents in the dimer molecules are omitted. Structures a and $\mathbf{b}$ are possible for complexes of ( $\mathrm{ZnHTPP})_{2}$ with $\mathrm{H}_{2} \mathrm{THP}\left(\mathrm{mPyr}_{4}\right.$ or $\mathrm{H}_{2} \mathrm{P}(\mathrm{mPyr})_{4}$ whereas structure $\mathrm{c}$ is realized for those with $\mathrm{H}_{2} \mathrm{P}(\mathrm{pPyr})_{4}$. tion of the central metal ions in metallocomplexes of tetrapyrrolic compounds with molecules having lone-pair electrons (e.g. dioxane) $[20,21]$. However, this approach was limited to the construction of long polymeric chains of pigment molecules only.

Recently we have applied a key-hole mechanism which is based on a modification of the abovementioned coordination method [22] and provides high complexation constants $\left(\approx 10^{7} \mathrm{M}^{-1}\right)$ for the construction of self-organized heterogeneous trimeric porphyrin assemblies [23-25]. In these aggregates $\mathrm{Zn}$-porphyrin or Zn-chlorin dimers are coordinated at two points (i.e. both the $\mathrm{Zn}$ ions in the dimer subunits are coordinated simultaneously by the same free base) by the nitrogen atoms of two pyridyl substituents of tetrapyrrolic molecules [23-25]. Phenyl-bridged chemical dimers of Zn-porphyrins have been shown to facilitate the complex formation (complexation constants up to $5 \times 10^{7} \mathrm{M}^{-1}$ ). This has been attributed to the fact that the $\mathrm{Zn}-\mathrm{Zn}$ distance in these dimers $(d=12.6 \AA$, Fig. 2) matches the $\mathrm{N}-\mathrm{N}$ distance between active sites in the free bases $l(l=10.0-15.1 \AA$, Fig. 2) as well as to the fact that their geometry is suitable for two-point coordination [25]. Additionally, the structure of the dimers and the free bases is flexible enough to compensate for small mismatches (of the order of 2 Å) existing for some of the dimer-ligand pairs [25].

Extending this approach of the two-point coordination of $\mathrm{Zn}$-porphyrin dimers we have succeeded in binding two $\mathrm{Zn}$-porphyrin chemical dimers via one molecule of tetrapyridyl-substituted porphyrin or tetrahydroporphyrin, i.e. to form pentameric complexes containing five macrocycles. Schematic structures of these complexes are shown in Fig. 1. In this Letter we discuss the formation and optical properties of pentameric complexes based on the $(\mathrm{ZnHTPP})_{2}$ chemical dimer and various tetrapyridyl-substituted free bases.

\section{Experimental}

The structures of the compounds used for self-assembling the pentameric aggregates are shown in Fig. 2. Synthesis and identification of the $\mathrm{Zn}$ porphyrin dimer, Zn(II)1,4-bis[5-(10,15,20-tri-phexylphenylporphyrinyl)]benzene or (ZnHTPP) $)_{2}$ are 
described in Ref. [25]. All the pyridyl-containing compounds $\left(\mathrm{H}_{2} \mathrm{THP}(\mathrm{mPyr})_{4}, \mathrm{H}_{2} \mathrm{P}(\mathrm{pPyr})_{4}\right.$ and $\mathrm{H}_{2} \mathrm{P}\left(\mathrm{mPyr}_{4}\right)$ used for complexation of ( $\left.\mathrm{ZnHTPP}\right)_{2}$ have been synthesized and purified according to known methods [26-30].

All experiments have been performed at room temperature using methylcyclohexane $(\mathrm{MCH})$ as solvent. This solvent was used since it has a low dielectric constant and does not form complexes with $\mathrm{Zn}$-porphyrins thus providing suitable conditions for the coordination of Zn-porphyrin dimers with pyridyl-containing extra-ligands.

The pentameric complexes were formed during a successive titration of a $(\mathrm{ZnHTPP})_{2}$ solution (concentration of $\left.(1-4) \times 10^{-6} \mathrm{M}\right)$ with a free base solution of a higher concentration ranging from $3 \times$ $10^{-5}$ to $1.6 \times 10^{-4} \mathrm{M}$. Absorption and fluorescence (excited at the isosbestic point observed in the absorption) spectra have been measured after each step of the titration procedure. The step, at which no further changes in the absorption of the dimer were detected within experimental error, was considered as the final point of the titration procedure.
The free bases were predissolved in $\mathrm{CH}_{2} \mathrm{Cl}_{2}$ to avoid precipitation from the solutions. After a titration procedure the concentration of $\mathrm{CH}_{2} \mathrm{Cl}_{2}$ in the final solution was less than $5 \mathrm{vol} \%$. Both $\mathrm{MCH}$ and $\mathrm{CH}_{2} \mathrm{Cl}_{2}$ (Aldrich, spectroscopic grade) were used without further purification.

Absorption spectra were recorded with a Shimadzu UV-3101PC UV-VIS-NIR scanning spectrophotometer. Table 1 presents the maxima of the absorption spectra and the molar decimal extinction coefficients of the studied monomeric compounds and their complexes. Fluorescence and fluorescence excitation spectra were measured with a Shimadzu RF-5001PC spectrofluorophotometer. Fluorescence spectra were corrected for the spectral response of the spectrometer.

The distances indicated in Fig. 2 have been determined using the structures simulated by aid of Hyperchem 1.02 software (method AM1 in the option Geometry Optimization). $d$ denotes the distance between the central $\mathrm{Zn}$ ions in the macrocyclic subunits of the $\mathrm{Zn}$-porphyrin dimer. $l$ is the distance between probable sites of the coordination for the free base
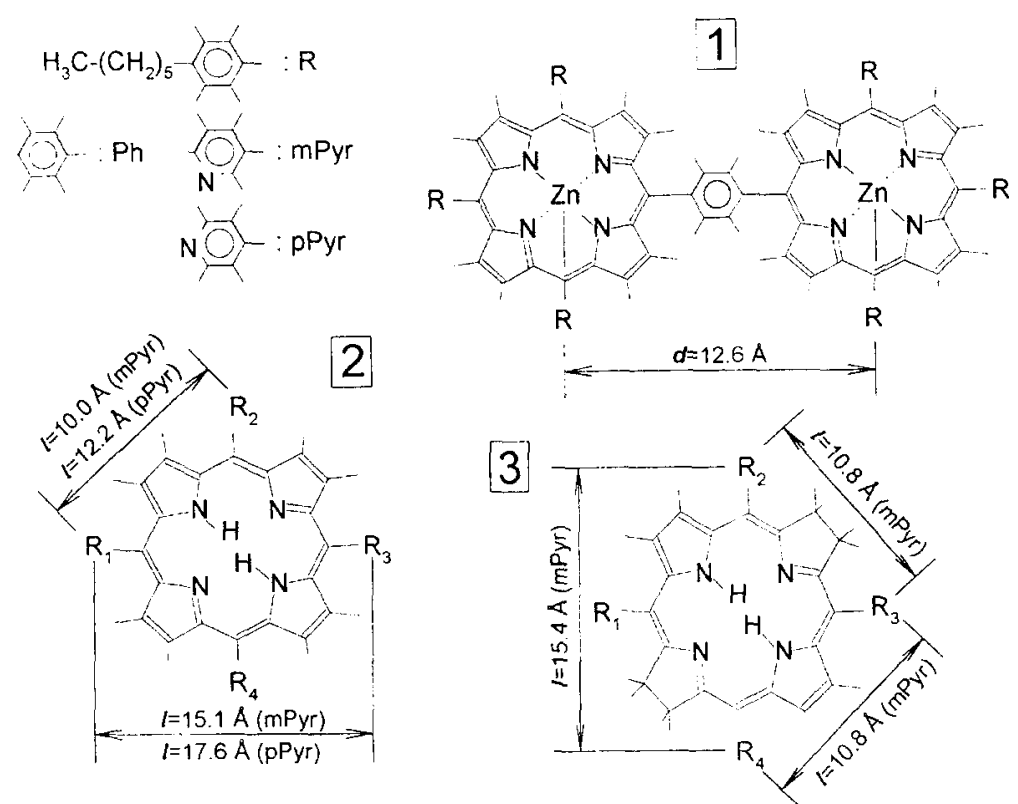

Fig. 2. Chemical structures of the compounds under investigation with indicated distances between central $\mathrm{Zn}$ ions $(d)$ in the dimers and nitrogen atoms of the pyridyl substituents $(l)$ in the free bases used. 1. (ZnHTPP) $; 2$ 2. $\mathrm{H}_{2} \mathrm{P}-(\mathrm{mPyr})_{2}: \mathrm{R}_{1}, \mathrm{R}_{3}:(\mathrm{mPyr}), \mathrm{R}_{2}, \mathrm{R}_{4}=\mathrm{Ph}$; $\mathrm{H}_{2} \mathrm{P} \wedge(\mathrm{mPyr})_{2}: \mathrm{R}_{1}, \mathrm{R}_{2}:(\mathrm{mPyr}), \mathrm{R}_{3}, \mathrm{R}_{4}: \mathrm{Ph} ; \mathrm{H}_{2} \mathrm{P}(\mathrm{mPyr})_{4}: \mathrm{R}_{1}, \mathrm{R}_{2}, \mathbf{R}_{3}, \mathbf{R}_{4}:(\mathrm{mPyr}) ; \mathrm{H}_{2} \mathrm{P}^{\wedge}(\mathrm{pPyr})_{2}: \mathrm{R}_{1}, \mathrm{R}_{2}:(\mathrm{pPyr}), \mathrm{R}_{3}, \mathrm{R}_{4}: \mathrm{Ph}_{2} \mathrm{H}_{2} \mathrm{P}(\mathrm{pPyr})_{4}$ $R_{1}, R_{2}, R_{3}, R_{4}:(\mathrm{pPyr}) ; 3 . \mathrm{H}_{2}$ THP-(mPyr) $)_{2}: R_{1}, R_{3}:(\mathrm{mPyr}), \mathbf{R}_{2}, \mathbf{R}_{4}=\mathrm{Ph} ; \mathrm{H}_{2} \mathrm{THP}(\mathrm{mPyr})_{4}: \mathrm{R}_{1}, \mathbf{R}_{2}, \mathbf{R}_{3}, \mathbf{R}_{4}:(\mathrm{mPyr})$. 


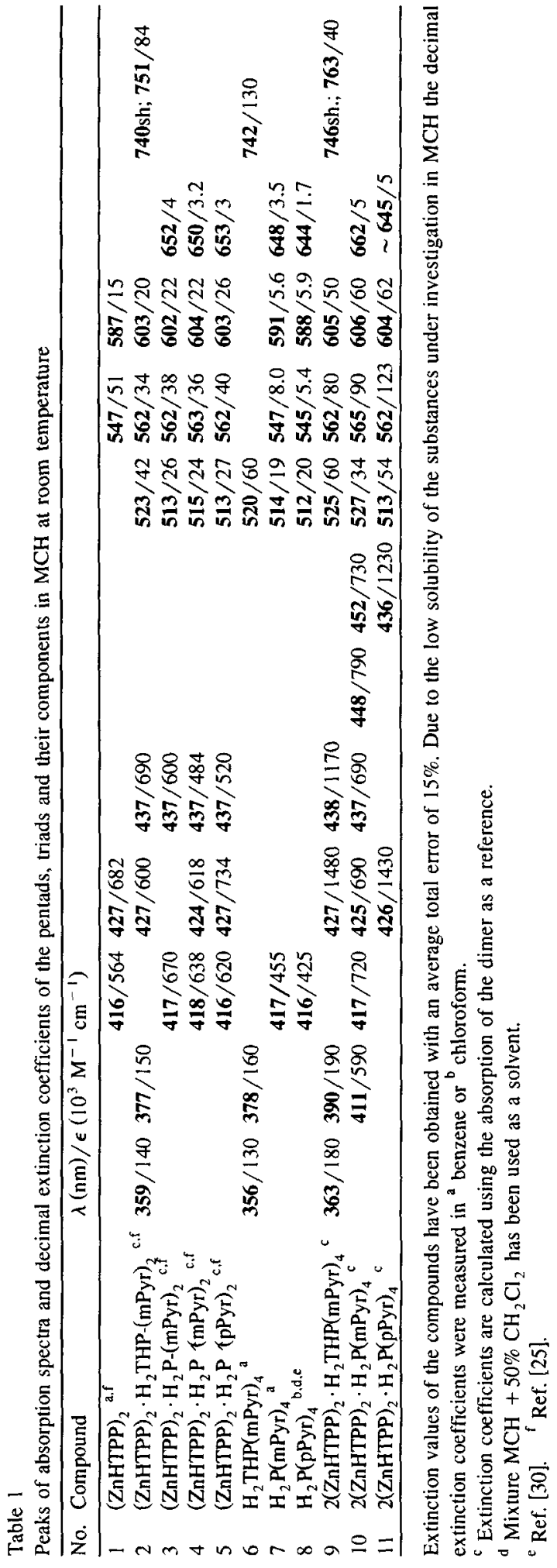

(ligand) molecules. This consists of the distance between the $N$ atoms of the pyridyl substituents in the free base molecules and the length of the $\mathrm{N} \cdots \mathrm{Zn}$ coordination bond. The distances $l$ are given for the conformations of the uncomplexed free bases which favor the two-point coordination of ( $\mathrm{ZnHTPP})_{2}$.

\section{Results and discussion}

The complexes formed by (ZnHTPP) ${ }_{2}$ with $\mathrm{H}_{2} \mathrm{THP}(\mathrm{mPyr})_{4}$ show the generic properties of pentameric complexes based on the double-point coordination of Zn-porphyrin dimers with pyridyl-substituted tetrapyrrolic ligands. Therefore, we use them to indicate the most typical features of these complexes. Variations in the optical properties of the pentameric complexes caused by changes in chemical structure of the ligands and the geometry of pyridyl substitution in them will be discussed in Section 3.2 using the complexes of (ZnHTPP) ${ }_{2}$ with $\mathrm{H}_{2} \mathrm{P}(\mathrm{pPyr})_{4}$ and $\mathrm{H}_{2} \mathrm{P}(\mathrm{mPyr})_{4}$.

\subsection{Complexation of $(\mathrm{ZnHTPP})_{2}$ with $\mathrm{H}_{2} \mathrm{THP}(\mathrm{mPyr})_{4}$}

\subsubsection{Formation of the complexes}

Similar to the results of our study on triadic systems [23,25], titration of a (ZnHTPP) ${ }_{2}$ solution with a solution of a tetrapyridyl-substituted free base was expected to result in the formation of complexes containing two dimer molecules both of which are attached to one molecule of free base via two-point coordination bonds as shown in Fig. 1.

Fig. 3a presents sequential changes in the absorption spectra observed during titration of a (ZnHTPP) solution with a $\mathrm{H}_{2} \mathrm{THP}(\mathrm{mPyr})_{4}$ solution. In the course of the titration the intensity of the absorption bands of the uncomplexed dimer (416 and $547 \mathrm{~nm}$ ) is gradually reduced. At the same time bands of $\mathrm{H}_{2} \mathrm{THP}(\mathrm{mPyr})_{4}(363,390,525$ and $763 \mathrm{~nm})$ appear which are shifted to the red as compared to the uncomplexed $\mathrm{H}_{2} \mathrm{THP}(\mathrm{mPyr})_{4}$ solution. Furthermore, the intensity of the set of peaks (438, 562 and 605 $\mathrm{nm}$ ) belonging to the complexed Zn-porphyrin dimer increases (Fig. 3a). The positions of the latter bands in the visible region are close to those observed for Zn-porphyrins and their chemical dimers complexed with pyridine $[25,31,32]$ or bifunctional ligands 
$[22,25]$. Therefore, these absorption bands can be clearly assigned to (ZnHTPP) ${ }_{2}$ coordinated with nitrogen atoms of the pyridyl groups in the $\mathrm{H}_{2} \mathrm{THP}(\mathrm{mPyr})_{4}$ molecules. Multiple isosbestic points $(400,432,533,555,590 \mathrm{~nm})$ observed in the absorption spectra of the titration mixture testify that predominantly only one product is formed as a result of the reaction leading to the described changes in the absorption spectra.

The absorption spectra of the dimer complexed with $\mathrm{H}_{2} \mathrm{THP}(\mathrm{mPyr})_{4}$ are compared to those obtained for the dimer complexed with the dipyridyl-containing ligand $\mathrm{H}_{2}$ THP-(mPyr) $)_{2}$ in Fig. 4a. (The spectra have been normalized to the intensity of the peaks near $560 \mathrm{~nm}$ ). As can be easily seen from this figure the bands belonging to the complexed dimer differ only by minor details including a certain intensity redistribution. The bands of the complexed free bases differ both in their intensity relative to the dimer bands and in position. The former is connected mainly with different relative concentrations of the free bases with respect to that of the dimer in the
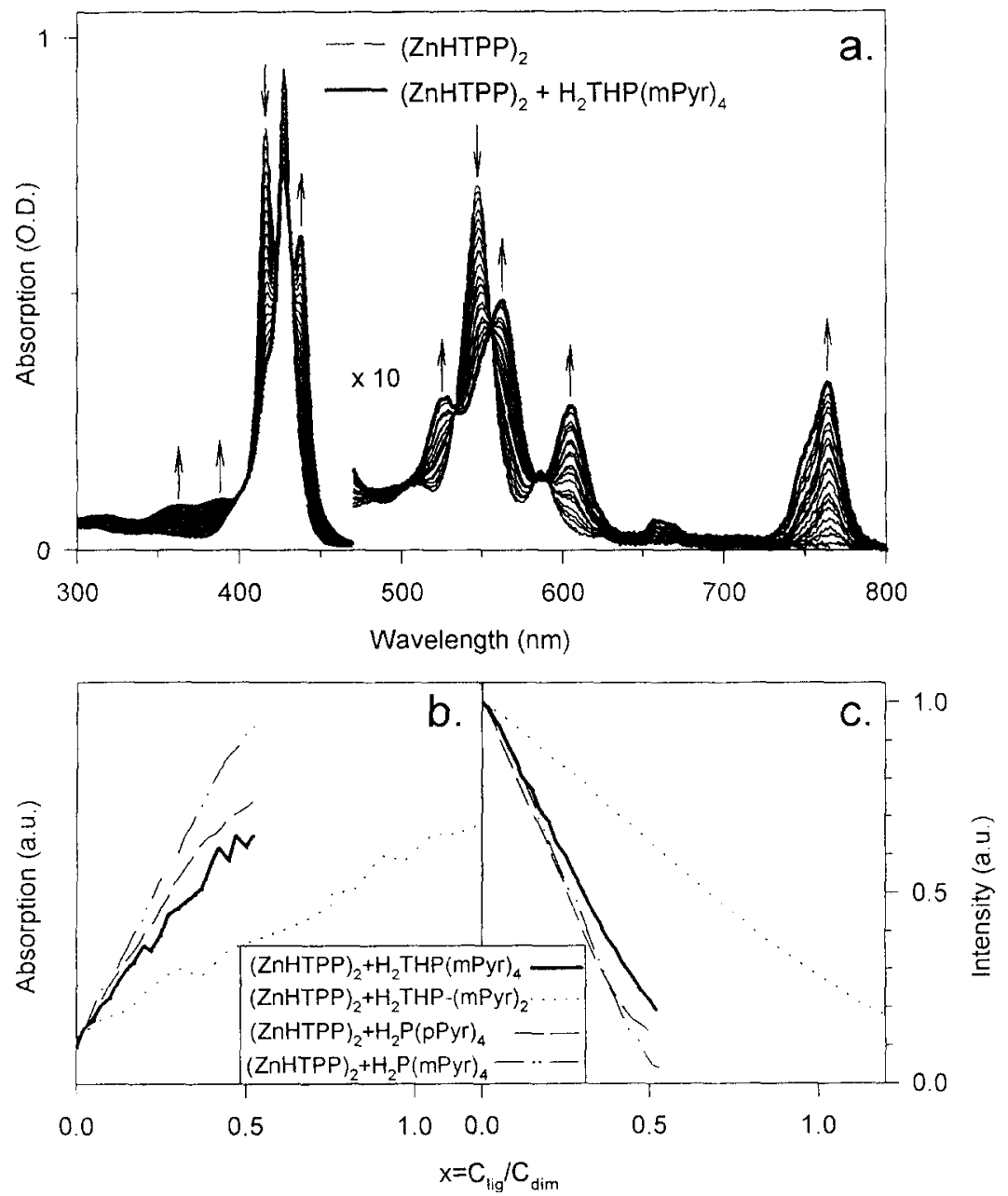

Fig. 3. Absorption spectra of a titration sequence for ( $\mathrm{ZnHTPP})_{2}$ with $\mathrm{H}_{2} \mathrm{THP}(\mathrm{mPyr})_{4}$ (a). Integral absorption of the complexed dimers (b) and fluorescence intensity of the uncomplexed dimers (c) in the titration mixtures of (ZnHTPP), with various free bases versus the ratio ( $x$ ) of the total free base and dimer concentrations in $\mathrm{MCH}$ at room temperature. Absorption in (b) has been integrated in the range from 604 to $625 \mathrm{~nm}$. Fluorescence intensity in (c) has been integrated from 580 to $596 \mathrm{~nm}$. Wavelength of fluorescence excitation in (c) was $555 \mathrm{~nm}$. 
solutions (ratio of the total concentrations of the free base and the dimer in the solution is $x=0.5$ and 1.3 for the (ZnHTPP $)_{2}+\mathrm{H}_{2} \mathrm{THP}\left(\mathrm{mPyr}_{4}\right.$ and $(\mathrm{ZnHTPP})_{2}+\mathrm{H}_{2} \mathrm{THP}-(\mathrm{mPyr})_{2}$ mixtures, respectively) and the latter will be discussed in detail in Section 3.1.2.

The absorption spectra of the (ZnHTPP $)_{2}+$ $\mathrm{H}_{2} \mathrm{THP}(\mathrm{mPyr})_{4}$ mixture near the final step of titration contain only a hardly detectable set of absorption bands (416 and $547 \mathrm{~nm}$ ) belonging to the uncomplexed dimer subunits (Fig. 4a). This means, that the abovementioned coordination bonds involve both of the (ZnHTPP) $)_{2}$ subunits.

Fig. 3 shows the integral absorption (b) of the pentads and the integral fluorescence intensity (c) of the uncomplexed dimer versus relative concentration of the free base $(x)$ in the titration solutions (for the sake of comparison the corresponding behavior of the related triad [25] is shown as well). As Figs. 3a and $4 \mathrm{a}$ indicate, spectral regions exist where predominantly the complexed dimers absorb, e.g. in the range of $437-460$ and $604-625 \mathrm{~nm}$. This gives us

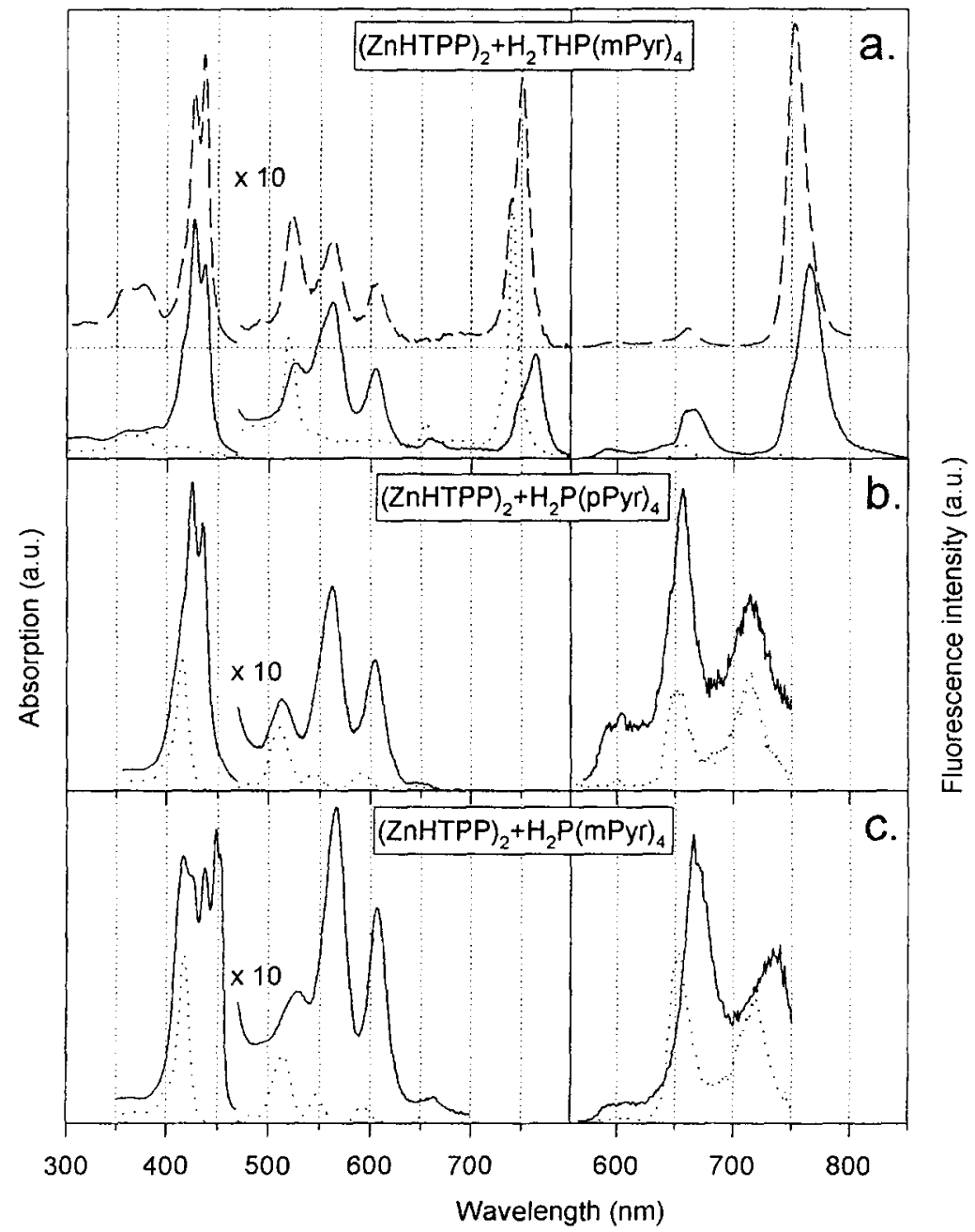

Fig. 4. Absorption (left) and fluorescence (right) spectra of the pentads ( - $(-)$ and those of the corresponding free bases ( . . . . ) taken at the same concentrations. (a) (ZnHTPP) $)_{2}+\mathrm{H}_{2}$ THP-(mPyr) $)_{4}$; (b) (ZnHTPP) ${ }_{2}+\mathrm{H}_{2} \mathrm{P}(\mathrm{pPyr})_{4}$; (c) (ZnHTPP) $)_{2}+\mathrm{H}_{2} \mathrm{P}(\mathrm{mPyr})_{4}$. In (a) the spectra of the (ZnHTPP) $)_{2}+\mathrm{H}_{2}$ THP-(mPyr) $)_{2}$ trimeric complex (a) (_- _- ) are included for the sake of comparison. The spectra have been measure for solutions in $\mathrm{MCH}$ at room temperature. Fluorescence was excitated at $\lambda_{\mathrm{ex}}=555 \mathrm{~nm}$. 
the possibility of using the integral absorption of the complexes as a measure of the total concentration of the complexes (Fig. 3b). However, a remaining contribution from the uncomplexed compounds hinders an accurate determination of the baseline of these curves.

On the other hand, as will be shown in Section 3.1.3, a reduction in the fluorescence intensity of the dimer, integrated over the blue slope of the uncomplexed dimer $\mathrm{Q}(0,0)$ band, can be used as a definite measure of the uncomplexed dimer concentration. The other compounds of the titration mixture do not contribute practically to the emission in the range of $580-596 \mathrm{~nm}$, which allows the use of the integral intensity without further correction (Fig. 3c).

A comparison of the (ZnHTPP $)_{2}+\mathrm{H}_{2}$ THP(mPyr) $)_{4}$ curves with the (ZnHTPP) $)_{2}+\mathrm{H}_{2}$ THP$(\mathrm{mPyr})_{2}$ ones in Figs. $3 \mathrm{~b}$ and $3 \mathrm{c}$ both for fluorescence and absorption shows that the concentration of the complexed dimers for the tetrapyridyl-substituted free base is almost doubled in comparison with that for the dipyridyl substituted free base at the same values of $x$ in the range $0-0.5$ and the end of titration occurs at $x \approx 0.5$. Taking into account that the triads make most of the solvates in the mixtures with the dipyridyl substituted free bases this means that the $2(\mathrm{ZnHTPP})_{2} \cdot \mathrm{H}_{2} \mathrm{THP}(\mathrm{mPyr})_{4}$ complexes prevail in the corresponding titration mixtures. In principle, an analogous titration behavior is possible when higher aggregates of the composition $\left.\left[2(\mathrm{ZnHTPP})_{2} \cdot \mathrm{H}_{2} \text { THP(mPyr }\right)_{4}\right]_{n}$ are formed. How ever, an allosteric effect found for the $\mathrm{Zn}_{2}$-gableporphyrins [22] and a lack of evidence on higher aggregate formation (e.g. precipitation) brings us to the conclusion that our expectations on the composition of the complexes were correct. This means that aggregates formed upon complexation of (ZnHTPP) ${ }_{2}$ with $\mathrm{H}_{2} \mathrm{THP}(\mathrm{mPyr})_{4}$ contain one molecule of the free base coordinating all four $\mathrm{Zn}$-ions in two molecules of the $\mathrm{Zn}$-porphyrin dimer by the nitrogen atoms of its pyridyl substituents. Hereinafter we refer to these aggregates as 'pentads' or 'pentameric arrays' since they contain five tetrapyrrolic macrocycles bound together using a combination of covalent and non-covalent supramolecular chemistry.

Structures of the pentameric complexes simulated with the aid of Hyperchem software show a complex distortion of all their subunits compensating for the mismatch of $d$ and $l$. Unfortunately, the structures resulting from the simulation are hardly understandable in the form of a two-dimensional picture. Therefore, in order to demonstrate the principal arrangement of the macrocyclic subunits we have used a schematic representation in Fig. 1. For the sake of clarity the macrocycles are planar, the length of bonds are abitrary and the substituents, uninvolved in coordination bonds, are omitted. The 2 (ZnHTPP) $)_{2}$. $\mathrm{H}_{2} \mathrm{THP}(\mathrm{mPyr})_{4}$ pentad might have either of the structures presented in Figs. $1 \mathrm{a}$ and 1b. However, it could not be concluded which of these structures really exist since the trimeric prototypes of these pentads have similar complexation constants as has been reported recently. (Complexation constants for (ZnHTPP) ${ }_{2} \cdot \mathrm{H}_{2} \mathrm{P}$-(mPyr) ${ }_{2}$ (prototype of the structure shown in Fig. 1a) and (ZnHTPP) $)_{2}$. $\left(\mathrm{H}_{2} \mathrm{P}^{\wedge}(\mathrm{mPyr})_{2}\right.$ (prototype of the structure shown at Fig. $1 \mathrm{~b})$ are $K_{C}=(6.5 \pm 0.7) \times 10^{6}$ and $(5.0 \pm 3.5)$ $\times 10^{6} \mathrm{M}^{-1}[25]$.)

Finally, one can readily calculate from the fluorescence data shown in Fig. $3 \mathrm{c}$ that about $80 \%$ of the solutes are bound in the pentameric complexes at $x=0.5$. Such a situation gives the possibility of investigating photophysical properties of the pentads with only minor contribution from the uncomplexed molecules.

\subsubsection{Electronic absorption of 2(ZnHTPP $)_{2}$ $\mathrm{H}_{2} \mathrm{THP}(\mathrm{mPyr})_{4}$}

Now let us consider the absorption of the $2(\mathrm{ZnHTPP})_{2} \cdot \mathrm{H}_{2} \mathrm{THP}(\mathrm{mPyr})_{4}$ pentad in more detail. The $\mathrm{Q}(0,0)$ absorption band of $\mathrm{H}_{2} \mathrm{THP}(\mathrm{mPyr})_{4}$ in the pentad exhibits a more pronounced redshift $\left(\Delta \nu_{\text {ats }}=\right.$ $370 \mathrm{~cm}^{-1}, \Delta \nu_{\mathrm{fl}}=410 \mathrm{~cm}^{-1}$ ) relative to the uncomplexed free base as compared to that of $\mathrm{H}_{2}$ THP$(\mathrm{mPyr})_{2}$ upon incorporation into the triad $\left(\Delta \nu_{\mathrm{abs}}=\right.$ $220 \mathrm{~cm}^{-1}, \Delta \nu_{\mathrm{fl}}=230 \mathrm{~cm}^{-1}$ [25]). (A shoulder in this band observed in the spectra of the (ZnHTPP) $+\mathrm{H}_{2} \mathrm{THP}\left(\mathrm{mPyr}_{4}\right.$ titration mixture can be clearly assigned to the low concentration of the (ZnHTPP) ${ }_{2}$ $\cdot \mathrm{H}_{2}$ THP(mPyr $)_{4}$ triad which is present in the mixture (compare the bands of the triads and the pentads in Fig. 4a).) This fact may be interpreted in terms of a larger distortion of $\mathrm{H}_{2} \mathrm{THP}\left(\mathrm{mPyr}_{4}\right.$ from planarity in the pentad relative to that of $\mathrm{H}_{2}$ THP-(mPyr $)_{2}$ in the triad. A correlation between the nonplanar deformation and the redshift of electronic absorption bands 
is known for various porphyrins [33]. Some geometrical mismatch exists between the active sites of the tetrapyridyl substituted free base with $l=10.8$ or $15.4 \AA$ and the central $\mathrm{Zn}$-atoms in the dimer with $d=12.6 \AA$ (Fig. 2 and Table 2). The deformations compensating for this mismatch are evident from the geometry simulations performed for both of the possible pentad structures, presented in Figs. $1 \mathrm{a}$ and $1 \mathrm{~b}$. In comparison with the ( $\mathrm{ZnHTPP})_{2} \cdot \mathrm{H}_{2}$ THP-(mPyr $)_{2}$ triad such a deformation in the pentad is larger or substantially different because of the obviously different compensation for the mismatches along one (in the triad) and two (in the pentad) axes, respectively. Therefore, the $2(\mathrm{ZnHTPP})_{2} \cdot \mathrm{H}_{2} \mathrm{THP}(\mathrm{mPyr})_{4}$ pentad is characterized by a larger redshift of the absorption bands of the free base with respect to that in ( $\mathrm{ZnHTPP})_{2} \cdot \mathrm{H}_{2}$ THP-(mPyr $)_{2}$.

As mentioned in Section 3.1.1 the components of the pentad Soret band have a different intensity distribution with respect to the (ZnHTPP) $)_{2} \cdot \mathrm{H}_{2}$ THP$(\mathrm{mPyr})_{2}$ triad without pronounced difference in their position (Fig. 4a). The structure of the dimer Soret band in the triads has been shown to reflect most likely the strong dipole-dipole coupling of the intense B-transitions of the dimer subunits [34] in a geometry distorted by the two-point coordination with the opposite metapyridyl substituents [35]. The difference between the pentad and the triad might be introduced by different geometries of the two-point coordination. A simple extension of the geometry of the $(\mathrm{ZnHTPP})_{2} \cdot \mathrm{H}_{2}$ THP-(mPyr $)_{2}$ triad would pro- duce the pentad structure given in Fig. 1a whereas the 2 (ZnHTPP $)_{2} \cdot \mathrm{H}_{2}$ THP(mPyr $)_{4}$ pentad could mostly have a structure presented in Fig. $1 \mathrm{~b}$.

Almost the same spectral position of the Soret band components and practically doubled extinction coefficients of the pentad compared to those of the triad (Table 1) bring us to the conclusion that the intense B-transitions of the individual dimers bound in the same pentad are not involved into strong coupling. Such a coupling would result in the appearance of additional splitting and substantial changes in the relative band intensities [34].

\subsubsection{Fluorescence of $2(\mathrm{ZnHTPP})_{2} \cdot \mathrm{H}_{2} \mathrm{THP}(\mathrm{mPyr})_{4}$}

Fluorescence spectra of the 2(ZnHTPP) $)_{2}$. $\mathrm{H}_{2}$ THP(mPyr $)_{4}$ pentad consist of emission bands of the free base mainly. The intensity of these bands is substantially higher (by factor of $\approx 50$ ) with respect to a $\mathrm{H}_{2} \mathrm{THP}(\mathrm{mPyr})_{4}$ solution containing the same concentration of the ligand under similar conditions of excitation (Fig. 4a). (An additional peak in the region of $660-670 \mathrm{~nm}$ is due to unavoidable $5-10 \%$ admixture of $\mathrm{H}_{2} \mathrm{Chl}(\mathrm{mPyr})_{4}$ in the sample of $\mathrm{H}_{2} \mathrm{THP}(\mathrm{mPyr})_{4}$. The admixture also forms a complex with (ZnHTPP) $)_{2}$. Therefore, its emission is sensitized as well.) According to the data obtained for other complexes with similar coordination $[23,25]$ the emission of the complexed ( $\mathrm{ZnHTPP})_{2}$ should be shifted to the red into the region of $609-611 \mathrm{~nm}$. However, only the strongly reduced (by factor of $\approx 7) \mathrm{Q}(0,0)$ fluorescence band of the uncomplexed

Table 2

Comparison of spectral shifts $(\Delta \nu)$ of $Q(0,0)$ bands of the subunits upon formation of various trimeric and pentameric complexes in $\mathrm{MCH}$ at room temperanure

\begin{tabular}{|c|c|c|c|c|}
\hline Complex & $\begin{array}{l}\Delta \nu_{\mathrm{abs}} \text { of }(\mathrm{ZnHTPP})_{2} \\
\left(\mathrm{~cm}^{-1}\right)\end{array}$ & $\begin{array}{l}\Delta \nu_{\text {abs }} \text { of the free base } \\
\left(\mathrm{cm}^{-1}\right)\end{array}$ & $\begin{array}{l}\Delta \nu_{\mathrm{fl}} \text { of the free base } \\
\left(\mathrm{cm}^{-1}\right)\end{array}$ & Mismatch $|d-l|(\AA)$ \\
\hline $\begin{array}{l}2(\mathrm{ZnHTPP})_{2} \cdot \mathrm{H}_{2} \mathrm{THP}(\mathrm{mPyr})_{4} \\
2(\mathrm{ZnHTPP})_{2} \cdot \mathrm{H}_{2} \mathrm{P}(\mathrm{mPyr})_{4} \\
2(\mathrm{ZnHTPP})_{2} \cdot \mathrm{H}_{2} \mathrm{P}(\mathrm{pPyr})_{4}\end{array}$ & $\begin{array}{l}540 \\
560 \\
510\end{array}$ & $\begin{array}{r}370 \\
330 \\
<110\end{array}$ & $\begin{array}{r}420 \\
345 \\
90\end{array}$ & $\begin{array}{l}1.6^{c} ; 2.0^{d} \text { or } 2.7^{e} \\
2.6^{d} \text { or } 2.5^{e} \\
0.4\end{array}$ \\
\hline $\begin{array}{l}(\mathrm{ZnHTPP})_{2} \cdot \mathrm{H}_{2} \mathrm{THP}(\mathrm{mPyr})_{2}{ }^{\mathrm{a}} \\
(\mathrm{ZnHTPP})_{2} \cdot \mathrm{H}_{2} \mathrm{P}(\mathrm{mPyr})_{2}\end{array}$ & $\begin{array}{l}480 \\
450\end{array}$ & $\begin{array}{r}220 \\
\approx 40\end{array}$ & $\begin{array}{l}230 \\
140\end{array}$ & $\begin{array}{l}2.7^{b} \\
2.5^{b}\end{array}$ \\
\hline$(\mathrm{ZnHTPP})_{2} \cdot \mathrm{H}_{2} \mathrm{P}^{\wedge}(\mathrm{pPyr})_{2}$ & 480 & $\approx 0$ & $\approx 0$ & 0.4 \\
\hline
\end{tabular}

${ }^{a}$ Ref. [25].

${ }^{b}$ Recalculated using the AM1 semi-empirical method since it provides more reliable results for the tetrapyrrolic molecules. The mismatches are calculated using $l$ (Fig. 2) for the adjacent metapyridyl substituents containing between them ${ }^{c}$ the hydrogenated or ${ }^{d}$ non-hydrogenated pyrrole ring as well as that for the ${ }^{\mathrm{e}}$ opposite metapyridyl substituents. 
dimer (peak at $594 \mathrm{~nm}$ ) is observed in the region of $590-620 \mathrm{~nm}$. Thus, we can conclude that similar to the triads investigated previously [25] the fluorescence of the dimer in the pentad is strongly quenched. At the same time, an energy transfer (ET) from ( $\mathrm{ZnHTPP})_{2}$ to $\mathrm{H}_{2} \mathrm{THP}(\mathrm{mPyr})_{4}$ is energetically favored (Table 1) and the fluorescence excitation spectra of the pentad consist mostly of the dimer bands (Fig. 5). Summarizing these facts we conclude that effective singlet-singlet ET takes place in the pentads. However, currently it is impossible to decide whether ET is the only intermolecular process leading to the dimer fluorescence quenching. Time-re-

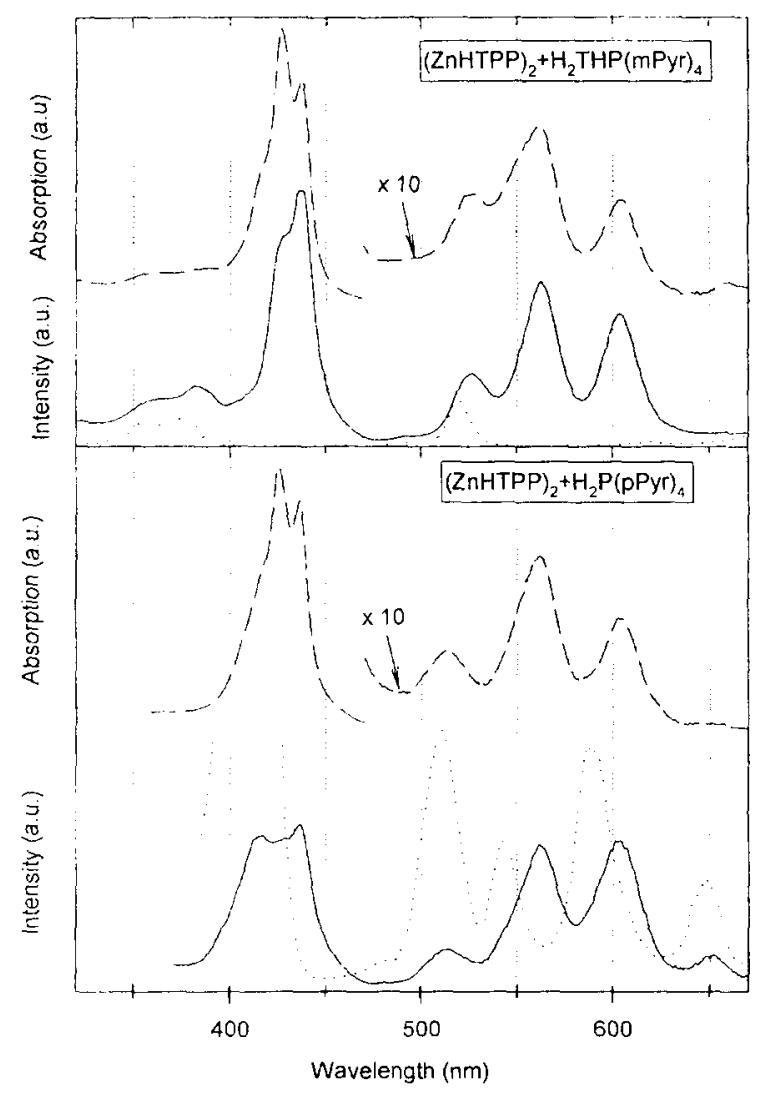

Fig. 5. Comparison of fluorescence excitation (- - ) and absorption (_- _- ) spectra of the pentads with the fluorescence excitation spectra of the corresponding free bases $(\cdots)$ ). (a): $2(\mathrm{ZnHTPP})_{2} \cdot \mathrm{H}_{2} \mathrm{THP}\left(\mathrm{mPyr}_{4} \text {; (b): 2(ZnHTPP }\right)_{2} \cdot \mathrm{H}_{2} \mathrm{P}(\mathrm{pPyr})_{4}$. The spectra have been measured in $\mathrm{MCH}$ at room temperature. Registration of fluorescence has been tuned to the $Q(0,0)$ peaks of the free base emission. solved measurements are underway to shed light on this problem.

3.2. Complexation of (ZnHTPP), with various tetrapyridyl substituted free bases

\subsubsection{Formation and structure}

Titration experiments using $\mathrm{H}_{2} \mathrm{P}(\mathrm{pPyr})_{4}$ (Fig. 4b) and $\mathrm{H}_{2} \mathrm{P}\left(\mathrm{mPyr}_{4}\right.$ (Fig. $4 \mathrm{c}$ ) have shown that the spectral behavior of the titration mixtures upon addition of the free base solution is almost the same as for $\mathrm{H}_{2} \mathrm{THP}\left(\mathrm{mPyr}_{4}\right.$ (Fig. 4a). Moreover, the titration curves for these free bases are similar to those obtained for $\mathrm{H}_{2} \mathrm{THP}(\mathrm{mPyr})_{4}$ (Figs. $3 \mathrm{~b}$ and $3 \mathrm{c}$ ). In the same manner as in Section 3.1.1 we conclude from these facts that these free bases form pentameric complexes with ( $\mathrm{ZnHTPP})_{2}$.

Since the spatial arrangement of the nitrogen atoms of the pyridyl rings in $\mathrm{H}_{2} \mathrm{P}\left(\mathrm{mPyr}_{4}\right.$ is close to that in $\mathrm{H}_{2} \mathrm{THP}(\mathrm{mPyr})_{4}$ a similar pentad structure is expected for $2(\mathrm{ZnHTPP})_{2} \cdot \mathrm{H}_{2} \mathrm{P}\left(\mathrm{mPyr}_{4}\right.$ and 2(ZnHTPP $)_{2} \cdot \mathrm{H}_{2}$ THP(mPyr) ${ }_{4}$ (Figs. la and lb). The situation is quite different for $\mathrm{H}_{2} \mathrm{P}(\mathrm{pPyr})_{4}$ where the nitrogen atoms are in the para position of the pyridyl rings. The lone pair orbitals are nearly in the plane of the $\mathrm{H}_{2} \mathrm{P}(\mathrm{pPyr})_{4}$ macrocycle while they form an angle of about $60^{\circ}$ with the macrocycle plane in the case of metapyridyl substituted free bases. This makes an arrangement of the $\mathrm{H}_{2} \mathrm{P}(\mathrm{pPyr})_{4}$ macrocycle in a plane parallel to the average plane of (ZnHTPP) $)_{2}$ unfavorable for a two-point coordination. This has been demonstrated already in studies of the complexation behavior of the dipyridyl substituted free bases with the parapyridyl substituents in the opposite $\left(\mathrm{H}_{2} \mathrm{P}-(\mathrm{pPyr})_{2}\right)$ and adjacent $\left(\mathrm{H}_{2} \mathrm{P}\right.$ ( $\left.(\mathrm{PPyr})_{2}\right)$ meso positions of the porphyrin macrocycle [25]. For the former no complexation enhanced by the two-point coordination is observed, as the nitrogen arrangement does not allow for this type of coordination with (ZnHTPP) $)_{2}$, whereas the (ZnHTPP) $)_{2} \cdot \mathrm{H}_{2} \mathrm{P}^{\wedge}$ (pPyr) $)_{2}$ triad is formed with a high complexation constant of $K_{\mathrm{C}}=(2.4 \pm 1.0) \times$ $10^{7} \mathrm{M}^{-1}$ [25]. An extension of the structure simulated in Ref. [25] for the ( $\mathrm{ZnHTPP})_{2} \cdot \mathrm{H}_{2} \mathrm{P}$ (pPyr $)_{2}$ triad to the case of pentameric complexes with $\mathrm{H}_{2} \mathrm{P}(\mathrm{pPyr})_{4}$ results in a structure depicted in Fig. 1c.

The similar behavior of titration curves for $\mathrm{H}_{2} \mathrm{P}(\mathrm{pPyr})_{4}$ and $\mathrm{H}_{2} \mathrm{P}(\mathrm{mPyr})_{4}$ compared to those of 
$\mathrm{H}_{2}$ THP(mPyr) $)_{4}$ (Fig. 3c) shows that concentrations of the uncomplexed compounds are also low in the titration solutions at $x=0.5$.

\subsubsection{Electronic absorption}

The absorption spectrum of the 2(ZnHTPP $)_{2}$. $\mathrm{H}_{2} \mathrm{P}$ (pPyr) ${ }_{4}$ (Fig. 4b) pentad in the range $470-700$ $\mathrm{nm}$ consists mainly of the bands belonging to the complexed dimers which are almost the same as in the $2(\mathrm{ZnHTPP})_{2} \cdot \mathrm{H}_{2} \mathrm{THP}(\mathrm{mPyr})_{4}$ spectrum (Fig. $4 \mathrm{a}$ ) and only slightly $\left(\approx 30 \mathrm{~cm}^{-1}\right)$ shifted to the red with respect to the corresponding triad (Table 2). For the $2(\mathrm{ZnHTPP})_{2} \cdot \mathrm{H}_{2} \mathrm{P}(\mathrm{mPyr})_{4}$ pentad (Fig. 4c) the spectrum is similar but the redshift is more pronounced $\left(110 \mathrm{~cm}^{-1}\right.$, Table 2). This redshift of the complexed dimer bands in the pentads relative to those in the corresponding triads can be assigned to a slightly more nonplanar conformation of the (ZnHTPP) ${ }_{2}$ macrocyclic subunits in the pentads which is caused in turn by the larger distortion of the free base macrocycle in the pentads (see discussion in the section below). However, these additional redshifts do not affect the common spectral behavior of the pentads. Summarizing these facts and taking into account the discussion in Section 3.1.1, one may conclude that the change in the visible absorption bands of the dimer upon formation of the pentads is caused mainly by the ligation of the dimer subunits with the nitrogen atoms of the pyridyl substituents. The geometry of the two-point coordination (para- or metapyridyl substitution of the free bases) and the chemical nature of the substituted free bases (porphyrin or tetrahydroporphyrin) have only minor influence on the spectral behavior in this case.

The same conclusion is valid for the absorption of the $2(\mathrm{ZnHTPP})_{2} \cdot \mathrm{H}_{2} \mathrm{THP}(\mathrm{mPyr})_{4}$ and $2(\mathrm{ZnHTPP})_{2}$ - $\mathrm{H}_{2} \mathrm{P}(\mathrm{pPyr})_{4}$ pentads in the Soret band region (Figs. $4 \mathrm{a}$ and $4 \mathrm{~b}$, Table 1). An analysis of this region shows that the bands of the $2(\mathrm{ZnHTPP})_{2} \cdot \mathrm{H}_{2} \mathrm{THP}\left(\mathrm{mPyr}_{4}\right.$ and $2(\mathrm{ZnHTPP})_{2} \cdot \mathrm{H}_{2} \mathrm{P}(\mathrm{pPyr})_{4}$ pentads are similar to those of the corresponding triads and each other apart from minor spectral shifts $\left(<100 \mathrm{~cm}^{-1}\right)$. From these facts one can conclude that the absorption in the Soret region of these two pentads is determined by the same effects as in the trimeric complexes, i.e. by ligation effects [25]. Furthermore, as discussed already for the $2(\mathrm{ZnHTPP})_{2} \cdot \mathrm{H}_{2} \mathrm{THP}(\mathrm{mPyr})_{4}$ pentad (see Section 3.1.2), no indications of strong coupling of the intense B-transitions of the individual $\mathrm{Zn}$ porphyrin dimers bound in the $2(\mathrm{ZnHTPP})_{2}$. $\mathrm{H}_{2} \mathrm{P}(\mathrm{pPyr})_{4}$ pentad, e.g. the appearance of additional components in the Soret band splitting, are observed. Finally, as in the triads [35] there is no evidence for a strong coupling of the B-transitions of the complexed free bases with those of the dimer subunits.

However, the Soret region of the $2(\mathrm{ZnHTPP})_{2}$. $\mathrm{H}_{2} \mathrm{P}(\mathrm{mPyr})_{4}$ pentad contains narrow bands at 448 and $452 \mathrm{~nm}$, in addition to the split components near 427 and $437 \mathrm{~nm}$ characteristic of the triads and the other pentads (Fig. 4c). The intensity of these bands with respect to the visible bands belonging to the dimer subunits is almost two times lower compared to the Soret bands of the other pentads (Fig. 4 and Table 1). Thus, besides the same type of the free base tetrapyridyl substitution the 2(ZnHTPP) ${ }_{2}$. $\mathrm{H}_{2} \mathrm{THP}\left(\mathrm{mPyr}_{4}\right.$ and $2(\mathrm{ZnHTPP})_{2} \cdot \mathrm{H}_{2} \mathrm{P}(\mathrm{mPyr})_{4}$ pentads have substantially different spectral features in the Soret region. One of the possible explanations could be that because of differences in structure of the free bases $\mathrm{H}_{2}$ THP(mPyr $)_{4}$ and $\mathrm{H}_{2} \mathrm{P}(\mathrm{mPyr})_{4}$ these pentads have different structures e.g. structures $\mathbf{b}$ and a shown in Fig. 1, respectively. In this case, a closer mutual arrangement of the dimer subunits in the $2(\mathrm{ZnHTPP})_{2} \cdot \mathrm{H}_{2} \mathrm{P}(\mathrm{mPyr})_{4}$ pentad (an interdimer separation of $\approx 8 \AA$ for structure a compared to $\approx 16 \AA$ for structure b) could facilitate an additional strong coupling between them. However, this point of view is hard to adopt without any other additional proof since the formation of structure a only for the $2(\mathrm{ZnHTPP})_{2} \cdot \mathrm{H}_{2} \mathrm{P}(\mathrm{mPyr})_{4}$ pentad looks like an exclusion among other combinations of the dimers and the free bases. For instance, the similar pentad $2(\mathrm{ZnOEP})_{2} \mathrm{Ph} \cdot \mathrm{H}_{2} \mathrm{P}(\mathrm{mPyr})_{4}$ shows only two components in the Soret region with the redshift $(\Delta \nu \approx 630$ $\mathrm{cm}^{-1}$ ) with respect to ( $\left.\mathrm{ZnOEP}\right)_{2} \mathrm{Ph}$ which is usual for the ligation [35].

Another explanation could be based on the easy precipitation of the $2(\mathrm{ZnHTPP})_{2} \cdot \mathrm{H}_{2} \mathrm{P}(\mathrm{mPyr})_{4}$ complex from a titration solution with the formation of visible flake-like structures (this is an exclusion among the pentameric complexes!). This might give evidence that certain higher order aggregates consisting of pentameric elementary cells (see a discussion in Section 3.1.1) are formed. In such an aggregate the dimers could be in contact close enough to produce the observed large splitting of the Soret 
band. Surely, both hypotheses must be proven on the basis of additional experimental investigations of the complex structure.

A comparison of the absorption spectra of free bases within the pentads with those of the uncomplexed molecules (Fig. 4 and Tables 1,2) shows that the $\mathrm{Q}(0,0)$ band of $\mathrm{H}_{2} \mathrm{P}(\mathrm{pPyr})_{4}$ is shifted only slightly whereas the redshift of those for $\mathrm{H}_{2} \mathrm{P}(\mathrm{mPyr})_{4}$ and $\mathrm{H}_{2} \mathrm{THP}(\mathrm{mPyr})_{4}$ is more pronounced. As compared to the complexes with the corresponding dipyridyl substituted free bases [25] the observed spectral shifts reveal the same tendency but are more pronounced. This fact can be understood taking into consideration several effects.

The macrocycles of the free bases in the pentads are distorted to a nonplanar conformation like in the case of $\mathrm{H}_{2} \mathrm{THP}(\mathrm{mPyr})_{4}$ (see discussion in Section 3.1.2) because of the mismatch between the arrangements of the active sites in the free bases and the central $\mathrm{Zn}$ atoms in the dimers. The mismatch for the $2(\mathrm{ZnHTPP})_{2} \cdot \mathrm{H}_{2} \mathrm{P}(\mathrm{pPyr})_{4}$ pentad is the smallest with respect to the other pentads (Table 2 ) therefore the deformation in this case should also be small. The mismatches in the $2(\mathrm{ZnHTPP})_{2} \cdot \mathrm{H}_{2}$ THP $(\mathrm{mPyr})_{4}$ and $2(\mathrm{ZnHTPP})_{2} \cdot \mathrm{H}_{2} \mathrm{P}(\mathrm{mPyr})_{4}$ pentads are similar but the hydrated porphyrin macrocycle of the free base in the former results in its higher flexibility [33] leading most probably to a larger deformation. Finally, as mentioned above, the non-planar deformation of the macrocycle correlates with the redshift of the visible absorption bands of the tetrapyrrolic compounds [33]. Thus, the tendency in the redshift of the $\mathrm{Q}(0,0)$ bands of the free bases in the pentads takes place most probably since their macrocycles are distorted from planarity to a different extent. Furthermore, the absorption bands of the dipyridyl-substituted free bases experience a smaller redshift upon formation of the complexes since these molecules are less deformed in the triads than the corresponding tetrapyridyl substituted free bases in the pentads (see Section 3.1.2).

\subsubsection{Fluorescence}

The fluorescence spectra of the 2(ZnHTPP $)_{2}$. $\mathrm{H}_{2} \mathrm{P}(\mathrm{pPyr})_{4}$ and $2(\mathrm{ZnHTPP})_{2} \cdot \mathrm{H}_{2} \mathrm{P}(\mathrm{mPyr})_{4}$ pentads are qualitatively the same as those of the $2(\mathrm{ZnHTPP})_{2} \cdot \mathrm{H}_{2}$ THP(mPyr $)_{4}$ pentad. This means that they consist mainly of the fluorescence bands of the free base ligands. Emission of the remaining uncomplexed dimers makes only a minor contribution to the spectra in the range 590-620 nm. Evidence for ET from the dimer subunits of the pentads to the free bases is given by the observation of quenching of the dimer emission with simultaneous sensitization of the free base fluorescence (Figs. 4 and 5) for these two pentads as well.

However, in contrast to the 2(ZnHTPP $)_{2}$. $\mathrm{H}_{2} \mathrm{THP}(\mathrm{mPyr})_{4}$ pentad (Fig. 5a), the intensity of the fluorescence excitation bands corresponding to the absorption of the free bases in the 2 ( $\mathrm{ZnHTPP})_{2}$. $\mathrm{H}_{2} \mathrm{P}(\mathrm{pPyr})_{4}$ (Fig. 5b) and 2(ZnHTPP $)_{2} \cdot \mathrm{H}_{2} \mathrm{P}(\mathrm{mPyr})_{4}$ pentads is substantially reduced (by a factor of $\approx 4$ 6 ) in comparison with similar spectra measured for a free base solution of the same concentration. This reduction means that upon inclusion of the free base molecules into these pentameric complexes an efficient deactivation process of their $S_{1}$ state comes into effect. The nature of this process (or processes) is not clear yet. In any case time-resolved measurements are necessary to clarify the electronic excitation energy deactivation paths in the pentameric complexes.

Finally, we would like to discuss the spectral shifts of the fluorescence bands characteristic of the free base subunits in the pentads with respect to the uncomplexed molecules. In all the pentads the 0-0 fluorescence bands of the free base subunits are shifted to the red. The extent of this shift grows over the pentad series 2(ZnHTPP $)_{2} \cdot \mathrm{H}_{2} \mathrm{P}(\mathrm{pPyr})_{4}$, 2 (ZnHTPP $)_{2} \cdot \mathrm{H}_{2} \mathrm{P}(\mathrm{mPyr})_{4}$ and 2 (ZnHTPP $)_{2}$. $\mathrm{H}_{2} \mathrm{THP}(\mathrm{mPyr})_{4}$ (Table 1) and definitely follows the tendency observed for the $\mathrm{Q}(0,0)$ absorption bands of the free bases which was discussed in Section 3.2.2. Evidently, the reasons for this behavior are telated to the non-planar deformation of the free base macrocycle in the complexes.

The extent of the redshift of the $Q(0,0)$ free base fluorescence bands is systematically larger than that of the $\mathrm{Q}(0,0)$ absorption bands (Table 2). This difference might be due to a certain structural rearrangement of the pentads during the lifetime of the $S_{1}$ state. Such a rearrangement could lead to a more nonplanar structure of the free base compensating for the usual expansion of the molecular wavefunction in an excited state. 


\section{Conclusion}

Self-organized pentameric porphyrin arrays have been formed due to a two-point coordination of $\mathrm{Zn}$ ions in two molecules of a chemical $\mathrm{Zn}$-porphyrin dimer, ( $\mathrm{ZnHTPP})_{2}$, with the nitrogen atoms of the pyridyl rings in the tetrapyridyl-substituted porphyrin and tetrahydroporphyrin free bases. Most of the free bases and the dimers are incorporated in selforganized pentads when the concentration of the free base is equal to half of the dimer concentration in the solution. Combinations of the dimer and the free bases have been chosen taking into account results of the previous work on formation of triadic complexes based on the two-point interaction. Thus, the method described can be considered as a way of formation of higher oligomeric aggregates with rather well defined structure.

The absorption bands of the pentameric complexes show a characteristic redshift of the order of $500 \mathrm{~cm}^{-1}$ attributed to the ligation effects found earlier for the trimeric complexes. An additional non-planar distortion of the free base macrocycles in the pentads leads to an additional redshift of their $\mathrm{Q}(0,0)$ absorption and fluorescence bands as compared to the corresponding free bases in the triads. The dimer molecules incorporated into the $2(\mathrm{ZnHTPP})_{2} \cdot \mathrm{H}_{2} \mathrm{P}(\mathrm{pPyr})_{4}, \quad 2(\mathrm{ZnHTPP})_{2}$. $\mathrm{H}_{2} \mathrm{THP}(\mathrm{mPyr})_{4}$ pentads are not involved in a strong interdimer coupling. However, the appearance of new red bands in the Soret region of ( $\mathrm{ZnHTPP})_{2}+$ $\mathrm{H}_{2} \mathrm{P}(\mathrm{mPyr})_{4}$ is assumed to be due to a strong coupling of dimeric subunits in a specific structure of this complex.

Singlet-singlet energy transfer from the complexed dimer molecules to the free base in the pentads is at least partly responsible for the observed dimer fluorescence quenching and the respective sensibilization of the free base subunit. However, different unidentified intermolecular processes of electronic excitation energy deactivation are effective in the $2(\mathrm{ZnHTPP})_{2} \cdot \mathrm{H}_{2} \mathrm{P}(\mathrm{pPyr})_{4}$ and (ZnHTPP $)_{2} \cdot \mathrm{H}_{2} \mathrm{P}(\mathrm{mPyr})_{4}$ pentads and lead to quenching of the free base fluorescence with respect to the uncomplexed molecules.

We are currently investigating picosecond timeresolved fluorescence decays at various temperatures to obtain a detailed mechanism of electronic energy deactivation in the pentads.

\section{Acknowledgements}

Financial support from the Volkswagen-Stiftung (Grant No. I/68 941) is gratefully acknowledged.

\section{References}

[1] K. Balzani and F. Scandola, Supramolecular photochemistry (Ellis Horwood, New York, 1991) pp. 89-196.

[2] K. Araki and H.E. Toma, J. Photochem. Photobiol. A 83 (1994) 245.

[3] M. Sirish and B.G. Maiya, J. Photochem. Photobiol. A 85 (1995) 127.

[4] B.A. Gregg and U. Resch, J. Photochem. Photobiol. A 87 (1995) 157.

[5] A. Osuka, K. Manyama, I. Yamazaki and N. Tamai, Chem. Phys. Letters 185 (1990) 392.

[6] C.A. Hunter, J.K.M. Sanders and A.J. Stone, J. Chem. Phys. 133 (1989) 395.

[7] M.R.Wasielewski, Chem. Rev. 92 (1992) 435

[8] J.-C. Chambron, A. Harriman, V. Heitz and J.-P. Sauvage, J. Am. Chem. Soc. 115 (1993) 7419.

[9] G.M. Dubowchik and A.D. Hamilton, J. Chem. Soc. Chem. Commun. No. 4 (1987) 293.

[10] A.K. Burrel, D.L. Officer and D.C.W. Reid, Angew. Chem. Intern. Ed. Engl. 33 (1995) 900.

[11] I. Abdalmuhdi and C.K. Chang, J. Org. Chem. 50 (1985) 410.

[12] T. Nagata, A. Osuka and K. Maruyama, J. Am. Chem. Soc. 112 (1990) 3054.

[13] V.S.-Y. Lin, S.G. DiMagno and M.J. Therien, Science 264 (1994) 1105.

[14] J. Davila, A. Harriman and L.R. Milgrom, Chem. Phys, Letters 136 (1987) 427.

[15] A. Osuka, K. Maruyama, N. Mataga, I. Yamazaki, N. Tamai and Y. Nishimura, Chem. Phys. Letters 181 (1991) 413.

[16] H.J. Schneider and H. Dürr, Frontiers in supramolecular organic chemistry and photo-chemistry (Verlag Chemie, Weinheim, 1991).

[17] J.L. Sessler, B. Wang and A. Harriman, J. Am. Chem. Soc. 117 (1995) 704, and references therein.

[18] J.F. Lipskier and T.H. Tran-Thi, Inorg. Chem. 32 (1993) 722.

[19] I. Salabert, T.H. Tran-Thi, H. Ali, J. van Lier, D. Houde and E. Keszei, Chem. Phys. Letters 223 (1994) 313.

[20] E.I. Zenkevich, A.P. Losev, G.A. Kochubeev and G.P. Gurinovich, J. Mol. Struct. 45 (1978) 423.

[21] M. Ikonen, D. Guez, V. Marvaud and D. Markovitsi, Chem. Phys. Letters 231 (1994) 93.

[22] I. Tabushi, S. Kugimiya, M. G. Kinnaird and T. Sasaki, J. Am. Chem. Soc. 107 (1985) 4192.

[23] U. Rempel, B. von Maltzan and C. von Borczyskowski, J. Luminescence 53 (1992) 175.

[24] E.I. Zenkevich, A.M. Shulga, A.V. Chernook, U. Rempel and C. von Borczyskowski, SPIE Proc. 2370 (1995) 126. 
[25] A. Chemook, E. Zenkevich, A. Shulga, U. Rempel and C. von Borczyskowski, J. Phys. Chem. 1995, in press.

[26] F.R. Longo, J.D. Finarelli and J.B. Kim, J. Heterocycl. Chem. 6 (1969) 927.

[27] H.W. Whitlock Jr., R. Hanauer, M.Y. Oester and B.K. Bower, J. Am. Chem. Soc. 91 (1969) 7485.

[28] B.P. Neri and G.S. Wilson, Anal. Chem. 44 (1972) 1002.

[29] R.G. Little, J.A. Anton, P.A. Loach and J.A. Ibers, J. Heterocycl. Chem. 12 (1975) 343.

[30] S. Sugata, S. Yamanouchi and Y. Matsushima, Chem. Pharm. Bull. 25 (1977) 884.
[31] J.R. Miller and G.D. Dorough, J. Am. Chem. Soc. 74 (1952) 3977.

[32] D. Gust, T.A. Moore, A.L. Moore, H.K. Kang, J.M. DeGraziano, P.A. Liddell and G.R. Seely, J. Phys, Chem. 97 (1993) 13637.

[33] M.O. Senge, J. Photochem. Photobiol. B 16 (1992) 3.

[34] R.L. Fulton and M. Gouterman, J. Chem. Phys. 41 (1964) 2280.

[35] C. von Borczyskowski, U. Rempel, E. Zenkevich, A. Shulga and A. Chernook, J. Mol. Struct. 348 (1995) 441. 